\title{
Intervenciones públicas en las periferias del sureste madrileño
}

\author{
Pilar Monreal Requena \\ Departamento de Antropología, \\ Universidad Autónoma de Madrid \\ pilar.monreal@uam.es
}

Resumen: Este artículo tiene como objetivo realizar un primer acercamiento a una comparación entre dos periferias del sureste madrileño, un asentamiento informal (la Cañada Real Galiana) y los nuevos PAU que se están desarrollando. Dicha comparación se hace posible mediante la reducción cada vez mayor del papel de las administraciones públicas, e implica una breve incursión en el concepto de periferias urbanas.

Palabras clavesः periferia; asentamiento informal; PAU; servicios públicos.

Abstract: This article aims to make a first approach to a comparison between two peripheries of the south-east of Madrid, an informal settlement (Cañada Real Galiana) and the new PAUSs that are being developed.This comparison is made possible by the increasing reduction of paper of public administrations, and implies a brief incursion into the concept of urban peripheries

Key Words: urban peripheries; informal settlement; PAUSs; public services. 
Según L. Wacquant (2013), lo que distingue al neoliberalismo es su prefijo "neo", que viene a caracterizar un cambio en el papel del Estadoः cambio definido por un incremento de su papel criminalizador y represor y, simultáneamente, un reforzamiento de su papel al servicio del capital, como incitador y benefactor de la economía de mercado. Como dice Foucault, en el curso del College de France de 1978-1979 (publicado en Foucault, 2013), el arte de gobernar bajo el neoliberalismo es el de ajustar la máquina del Estado a los mecanismos de la competitividad. Y esto significa una reversión en el papel del Estado: es el mercado el que regula al Estado, no viceversa. Por su parte, las aportaciones de Pierre Bourdieu (2002), con su concepto de «campo burocrático», señalan el papel dinámico del Estado, recordándonos que no es un agente monolítico y coherente, sino que, más bien, las administraciones públicas son un espacio de fuerzas y luchas, prerrogativas y prioridades, del poder público sobre su propio ámbito de actuación y, en particular, sobre la definición de "problemas sociales», cuáles son y cómo tratarlos. ${ }^{1}$

En este artículo pretendo comparar el papel de la administración pública en dos núcleos suburbanos de la Comunidad de Madrid: un asentamiento informal ubicado sobre una antigua cañada real, la Cañada Real Galiana, y las nuevas suburbanizaciones o PAU (Planes de Actuación Urbana) que la rodean, resultado de las directrices marcadas en el Plan General de Ordenación Urbana de Madrid (PGOUM) de 1997. Al comparar espacios tan diferentes lo hago con la intención de mostrar que comparten dos características: 1) ambos fenómenos son producto de políticas públicas ligadas al problema estructural de la vivienda en Madrid, la Cañada Real es un resultado de los modelos de desarrollo urbano que han caracterizado a Madrid desde los años cincuenta del siglo xx hasta la actualidad y los PAUS son el resultado de un crecimiento urbano orientado hacia la especulación y la acumulación; sin embargo, en ambas, actualmente la presencia de equipamientos y servicios públicos del Estado proveedor de bienes de consumo colectivo es casi inexistente; y 2) ambos asentamientos están ubicados en el sureste periférico madrileño.

1 Además, Bourdieu sugiere que en el Estado contemporáneo hay dos luchas internas: la de los dominados y dominantes, que enfrenta a aquellos responsables políticos partidarios de la protección social a los grupos sociales más desfavorecidos y aquellos partidarios del neoliberalismo y la mercantilización; y la batalla que él denomina «horizontal», representada por la lucha entre la derecha, compuesta por el capital cultural y el capital económico, y la izquierda, que desea proteger a la población despojada por estas formas de capital (cultural y económico). 
Antes quisiera hacer una brevísima descripción de ambos asentamientos urbanos.

\section{Cañada Real Galiana}

El poblamiento de la Cañada se llevó a cabo sobre una antigua vía pecuaria trashumante, la Cañada Real, a partir de finales de la década de los cincuenta del siglo xx. Al ser Patrimonio Histórico, las cañadas no pueden ser urbanizables y son espacios altamente regulados por las distintas administraciones desde la Edad Media y la creación de la Mesta (1273-1836). A partir la ley de 1995 se transfirieron sus competencias a las comunidades autónomas, y en el caso madrileño, culminó su proceso de desafección en 2011.

La Cañada es una verdadera ciudad lineal de 14 kilómetros de extensión donde residen censadas cerca de 8.000 personas en unas 2.700 viviendas; es, por lo tanto, el mayor asentamiento informal de la comunidad madrileña, y tal vez del país, según la Comunidad Autónoma de Madrid (2017). ${ }^{2}$ La Cañada atraviesa terrenos de tres ayuntamientos, Madrid (al que corresponde el $79,8 \%$ de su territorio y de la mayoría de sus habitantes), Rivas Vaciamadrid (al que pertenece el 10,5\%, y con 1.132 vecinos) y Coslada (con el 9,7\% y al que pertenecen 927), comenta el documento titulado Estrategia de Intervención Cañada Real Galiana (2015). Por lo tanto, la intervención pública en la Cañada es competencia de las tres administraciones: a) la estatal, a través de la Delegación del Gobierno de Madrid, que desempeña las tareas de información a los ciudadanos, orden público y seguridad ciudadana, inmigración y extranjería; b) la administración autonómica, propietaria del suelo y a la que compete la sanidad, la educación y lo social, y sobre todo es responsable del ordenamiento urbanístico; y c) los tres ayuntamientos implicados. Esta complejidad administrativa origina planes de intervención contradictorios y alianzas contra natura entre administraciones de diferente orientación política.

Es importante destacar su localización en el sureste madrileño, área donde se construyeron los barrios y municipios obreros. Su proceso de poblamiento se inició en los años cincuenta y sesenta del siglo xx, con la industrialización y el crecimiento urbano madrileño, donde se ubicaron inmigrantes procedentes del campo español o vecinos que no habían logrado vivienda en la capital madrile-

2 Según el mismo documento, habría unas 2.537 edificaciones, 
ña. En los años ochenta y noventa se siguió poblando con olas de inmigrantes fundamentalmente marroquíes y algunos latinoamericanos y con población desalojada de los demolidos núcleos chabolistas de La Celsa y Las Barranquillas, mayoritariamente de etnia gitana. Ya en la primera década de nuestro milenio, siguieron llegando nuevos pobladores, esta vez gitanos de origen rumano y portugués y familias expulsadas de Madrid por la carestía de la vivienda. Por lo tanto, y según el documento Estrategia de Intervención Cañada Real Galiana, la Cañada se caracteriza por una enorme diversidad étnica: el 26\% de sus residentes es de étnica gitana española (a los que hay que sumar gitanos rumanos y portugueses), y conviven con inmigrantes marroquíes (22\%), españoles no gitanos (34\%) y personas de otras nacionalidades (9\%). La heterogeneidad es también la nota que la caracteriza desde el punto de vista socioeconómico, del estado y condición de sus viviendas, de los servicios e infraestructuras, de los transportes y comunicaciones. Es decir, no hay una sola Cañada Real Galiana. Además, nos encontramos con una población no solo diversa étnicamente, sino con unos altos niveles de vulnerabilidad medida por nivel de estudios, actividad laboral, ingresos económicos y cobertura sanitaria (disponibilidad de tarjetas sanitarias), como señala el documento Estrategia de Intervención Cañada Real Galiana.

Pero sin esconder esa diversidad, es importante comentar que, excepto los tramos pertenecientes al municipio de Coslada e integrados en su trama urbana, toda la Cañada padece enormes deficiencias de infraestructura y equipamientos: los vecinos han pavimentado las escasas zonas de esta condición que hay y son los vecinos los responsables de la instalación de alumbrado público, sus viviendas no son solo ilegales al construirse sobre un espacio no urbanizable, sino que los enganches a la luz y el agua corriente se hacen de manera ilegal o muy precaria; a la mayoría de sus tramos no llega el transporte público, ni existen centros escolares, ambulatorios ni espacios públicos donde los vecinos y vecinas puedan reunirse. Además, a partir de los años noventa del siglo xx se han ido construyendo autovías, vías del AVE, incineradoras municipales..., que se convierten en un problema a la hora de aplicar la normativa urbanística «procedente de Europa», comenta un alto dirigente de la Comunidad de Madrid, para la legalización de las viviendas en materia de contaminación acústica, proximidad a vías rápidas de comunicación o sanitarias por cercanía a estercoleros. 
Por último, se ha convertido en la arena de una serie de intereses y necesidades, de planes y actuaciones, ya que, durante la última década (2011) es la protagonista de una "hiperintervención" por parte del sector público, pero también del privado: técnicos, trabajadores sociales de los distintos ayuntamientos, a los que se suman ONG (sobre el terreno llamadas "entidades sociales"), proyectos de convivencia comunitaria (ICI financiado por La Caixa), Cruz Roja, medios de comunicación, orden público..., trocando la Cañada en lo que Bourdieu llama "un espacio difícil", ya que en él convergen los intereses de las distintas administraciones públicas, la enorme heterogeneidad de residentes $y$ grupos sociales, mujeres, hombres, jóvenes, ancianos, niños/as, organizaciones y entidades sociales de comerciantes, empresariales y procesos de especulación endógenos y exógenos, lo que ha sido contestado desde los residentes con la creación de ocho asociaciones de vecinos. Por lo tanto, tienen también un complejo entramado social.

Quiero rescatar ahora un breve párrafo de mi diario de campo:

Entro en la única vía de circulación de la Cañada, sin aceras ni pavimentación, sin alumbrado - excepto el que los y las vecinas han instalado-, con basuras, llena de polvo en verano y barro en invierno, sin árboles ni bancos donde descansar los mayores y las mujeres que van y vienen acompañando a sus hijos a coger el autobús escolar o a comprar en algún puesto de venta ambulante; a veces pasan autos, la frecuencia depende de la zona, algunos de alta gama y velocidad rápida que todos saben a dónde van. A las puertas de las casas, tanto las noches cálidas de invierno como las mañanas templadas de primavera y otoño, grupos de vecinos se sientan a charlar o a tomar un té. No se ve a adolescentes en la calle (el único bar donde se reunían, en el sector 3, se cerró hace un par de años por jubilación de la propietaria). Pero hay muchos niños que juegan en la calle. Nos podemos cruzar frecuentemente con mayores marroquíes que van hacia las mezquitas de los sectores 5 y 6 . Detrás o delante de las casas podemos ver huertos familiares o jardines de distintos tamaños dependiendo del sector. En otras ocasiones, como en los sectores 3 y 4, hay muros de adobe o ladrillo que impiden ver al transeúnte lo que hay detrás (las viviendas de una familia gitana ampliada con numerosos núcleos conyugales, una nave de electrodomésticos o un almacén de material de construcción, un bonito jardín...). La Cañada, sin pavimentar, sin alcantarillado, sin electricidad, rezuma vida y hay alegría en su única calle, excepto si entramos en los 
dominios de las numerosas viviendas que han sido demolidas en el sector 3, 4,5 y 6: los escombros se acumulan (las familias no solo han perdido su casa, sino que han tenido que pagar una multa y el precio de la recogida de los escombros, unos 1.500 euros). Entre las ruinas de las antiguas viviendas, ahora hay ratas, desperdicios, destrucción, desolación o se ha levantado una nueva vivienda, ahora sí, convertida en chabola. Otras veces, la Cañada se llena de risas, música, gente, canciones..., y los niños corren con las caras pintadas tras una charanga, un pasacalle, o una batuka: alguna asociación está celebrando una fiesta en alguna de las sedes de las asociaciones de vecinos o en La Casita: carnavales, Navidades, Acción Global, comida o tortillada de primavera, campamentos de verano para los niños, incluso una romería que organiza una peña rociera del sector 4 (Cuaderno de campo, 23 de marzo de 2014).

Con esta descripción he querido resaltar la vida en la antigua vía pecuaria, pero quiero destacar la nula presencia de la administración pública, solo visible a través de los servicios sociales (529 de sus 2.149 familias reciben el RMI, ${ }^{3}$ Comunidad de Madrid, 2017) y la policía, estratégicamente situada en las salidas a las autovías circundantes, o la Guardia Civil, circulando por la antigua cañada.

Sin embargo, la Cañada padece un proceso de estigmatización que la identifica con el tráfico y los clanes de la droga y los robos de autos y de cobre, hasta ser denominada «el supermercado de la droga de Madrid». Su diversidad es anulada, invisibilizada, y es considerada un espacio peligroso y violento, y las duras incursiones de la policía son frecuentes en ella, ya sea en forma de redadas contra la droga, ya sea por los derribos ordenados por Disciplina Urbanística del Ayuntamiento de Madrid o de otro municipio. Es cierto que el problema de las drogas se da en la Cañada, pero solo en 1,5 kilómetros de sus 14 de extensión, y actualmente se está expandiendo a otras partes por el acoso policial.

El cambio de ser considerada por la opinión pública y los medios de comunicación como una población pobre, que ha de ser realojada, víctima de las políticas de viviendas de Madrid y de la dejadez y desidia de una administración local, a ser considera el mercado de la droga de Madrid, unos aprovechados que quieren vivir del patrimonio de todos, es decir, de ser «víctimas» a ser «criminales», se realiza a partir de 1995 (Monreal, 2014). Es el momento en el que las

3 Renta Mínima de Inserción Madrileña. 
cañadas pasan a ser competencia de las comunidades autónomas y en el que las administraciones públicas autonómicas y locales madrileñas apuestan por una política urbanística basada en los megaproyectos y las grandes urbanizaciones residenciales, apuesta que se consagró en el Plan General de Ordenación Urbana de 1997. Así, cerca del asentamiento de la Cañada se planificó y se inició la construcción de tres PAU y del centro comercial de La Gavia, el mayor de la Comunidad de Madrid. En un recorrido a lo largo de todo el asentamiento informal podemos ver cómo, tras la hilera de casas en torno a la antigua vía pecuaria, aparece un bosque de grúas entre kilómetros y kilómetros de terreno parcelado con una infraestructura incipiente: carreteras, calles, alumbrado público, alcantarillado y ya núcleos de chalés adosados construidos. Son los PAU de Los Ahijones y El Cañaveral, muchas de cuyas viviendas se están entregando desde 2014. Por lo tanto, el asentamiento informal es limítrofe con estas suburbanizaciones, hasta tal punto que algunas de las viviendas y huertos de la Cañada se asientan sobre El Cañaveral, y la antigua vía pecuaria se ha convertido en un problema para los procesos de especulación que implica el modelo de crecimiento mediante PAU (Monreal, 2014b).

\section{Los PAU del sureste madrileño}

A la espera de resultados de trabajo de campo más etnográficos y definitivos, vamos a hablar de los PAU que rodean a la Cañada Real, especialmente El Cañaveral-Los Berrocales, y de referencias a PAU más consolidados como el de Vallecas. Estos modelos de crecimiento urbano son considerados por muchos autores como una manifestación de la ciudad neoliberal.

El PAU de El Cañaveral es un hiperbarrio ubicado en el suroeste madrileno, rodeado por las autovías de circunvalación M45 y M50. Su construcción se inició en 2013. Tras la crisis inmobiliaria de 2007, este PAU se ha adaptado a las nuevas condiciones expresadas por la Consejería de Medio Ambiente y Ordenación del Territorio, donde se prima la construcción a fases (una fase construida y vendida sirve para financiar la construcción de la siguiente). El Cañaveral, perteneciente al distrito madrileño de Vicálvaro, limita al este con la Cañada Real, al norte, con el municipio de Coslada, y al sur, con otro futuro PAU, el de Los Ahijones. Tiene una superficie total de $538 \mathrm{Ha}$, de las que 100 estaban dedicadas en su plan parcial a zonas verdes (que incluían la 
Cañada como una senda ecológica), donde se preveía también la construcción total de 14.000 viviendas, el $53 \%$ con algún régimen de protección, en especial viviendas de protección pública básica (VPPB). Las viviendas de los primeros propietarios se iniciaron a principios de 2013 en régimen de cooperativa financiadas por el Banco Santander, y las primeras viviendas se entregaron en otoño de 2014. Los precios oscilan entre los 168.365 y los 199.440 euros. Su publicidad se basa en lemas como "Seguridad y seriedad", "Diseño exclusivo" y "Calidad y confort" (<http://www.youtube.com/watch?v=EkA85Fa4WEo\& feature =youtu.be\&hd=1>, consultado por última vez el 22 de junio de 2017).

En 2016 sumaba ya unas 900 viviendas acabadas, 520 en edificación, 600 pendientes de iniciarse este año y 1.350 con licencia concedida o fruto de la permuta de suelos entre Los Berrocales y Los Ahijones. Los 600 vecinos que las ocupan en la actualidad se encuentran en una zona carente de servicios, equipamientos y transporte público, abandonados en medio de un páramo de nadie.

En general, los PAU tienen tanto residencias unifamiliares adosadas como bloques de pisos de unas cuatro o cinco alturas (en ocasiones llegan hasta ocho), planificadas para viviendas tanto de clase trabajadora como de las clases ligadas al Madrid global. Los bloques de viviendas están diseñados en manzanas de vecinos, como un espacio intermedio entre la vida pública y la privada. Por ejemplo, en el consolidado PAU de Vallecas, el dominio del diseño ronda lo absurdo, habiendo recibido sus viviendas (sociales, de realojo) diversos premios de arquitectura nacionales e internacionales. Hay una marcada diferencia entre las promociones públicas y privadas. En las primeras los espacios públicos son inexistentes o están a medio acabar, siendo los vecinos con sus iniciativas quienes están plantando flores y árboles para tener parques. Los residentes en urbanizaciones de promoción privada cuentan con fuertes medidas de control (portero automático de claves, puertas de acceso controladas por vídeo, ascensores con llave, guardias de seguridad), zonas ajardinadas, piscinas e instalaciones deportivas comunitarias. Son áreas residenciales con acceso restringido, pobladas por una clase media, donde los espacios públicos han sido normalmente privatizados o abandonados, donde se desarrolla una homogeneidad social, un «estilo de vida verde», pautas de consumo y ocio y estrategias de diferencia social e identidades específicas (Espallarga, 2016). 
Según el trabajo etnográfico de Dorina Martínez (Martínez y López Díaz, 2016), los vecinos consideran "las viviendas muy grandes, pero de mala calidad los materiales, los acabados". Sus calles desiertas chocan con el colorido y la vida de la Cañada, las anchas avenidas solo son utilizadas por los automóviles y están sin transporte público. Viviendas estéticas pero edificadas con materiales deficientes, que a los pocos años de su entrega han de ser reparadas, y que no satisfacen las necesidades de nadie. Obras de arquitectura - financiadas con dinero público - que nadie utiliza ni disfruta (el Ecobulevar de Vallecas), que son protagonistas de lo que se ha denominado "turismo arquitectónico", pero que nada tiene que ver con los vecinos. Falta de interés, impagos, ocupaciones, edificios «muy originales, muy diferentes», con habitaciones inadecuadas (una vecina se queja de que en su edificio — del IVIMA— "el salón es circular [...] muy original y todo eso, pero claro, para amueblarlo o pierdes muchos metros o con el tipo de muebles que hay tienes que hacer muebles a medida, $y$ eso no...") (Martínez y Lopéz Díaz, 2016: 12). Espacios públicos sin terminar, equipamientos a medio hacer, inexistencia de servicios educativos, sanitarios, colectivos. Para satisfacer las necesidades de educación, salud o transporte de sus vecinos, la población se ve obligada a acudir a la iniciativa privada aquellos que se la puedan pagar o a recorrer grandes trayectos los que no pueden. El último dislate de este proceso fue la venta de más de 1.860 viviendas propiedad de la Empresa Municipal de Vivienda Social (EMVS) habitadas por vecinos de bajos ingresos a fondos buitre norteamericanos en el verano de 2012. A los vecinos nunca se les comunicó la modificación de sus contratos.

Tendremos que esperar a los resultados de las tesis doctorales que se están realizando en la actualidad sobre los PAU para conocer más sobre su sociabilidad, identidad, asociacionismo, etc. Pero mientras tanto podemos recurrir a la etnografía de José Luis Espallargas (2016), que, trabajando sobre varias suburbanizaciones de Tarragona, sostiene la existencia de una "sociabilidad selectiva [... ] que elige dónde, cuándo y con quién” (ob. cit.: 327) socializar en ausencia de un espacio público (aunque como un comentario al autor, yo añadiría que su trabajo se centra en una población que elige porque su nivel socioeconómico le permite elegir) y "nuevos perfiles de identidad híbrida". 
Las biografías de los habitantes suburbanos investigados son una constante construcción de identidades diferenciadas y disgregación (incluso en el sentido geográfico del término, como explica en communiting). No se trata de fijar un «yo» inamovible como antaño, sino de navegar entre identidades (Espallargas, 2016:349-350).

Mientras tanto, la Cañada Real se sitúa en el otro polo del orden, planificación, estetificación, funcionalidad, individualización y homogeneización que caracterizan a los PAU.

Por otro lado, ambos espacios comparten su posición de periferias urbanas y esta condición nos lleva a enfrentarnos a un concepto que, como el de periferia, está lejos de estar claramente definido. Algunos autores datan su origen en el crecimiento industrial y urbano del siglo $\mathrm{xx}, \mathrm{y}$, en los últimos años, se ha replanteado el debate sobre las periferias urbanas de la mano de los procesos de suburbanización y su diversidad, ya sea como "countries" (Svampa, 2003) o "barrios enrejados" (Low, 2001, 2003, 2006), "condominios" (Caldeira, 2007). En dicho debate participan geógrafos, urbanistas, sociólogos y antropólogos; en España, cabe destacar el trabajo etnográfico de una nueva generación de jóvenes antropólogos y antropólogas (Aramburu, 2017; Ávila, 2015; García, 2011; González Cueli y Vaquerizo, 2015, 2017).

La perspectiva hegemónica de geógrafos y urbanistas (Arteaga, 2005; Rafael Más, 1999; Valenzuela, 2003) adolece de una visión técnica y territorial, donde no toman en cuenta lo social y mucho menos los temas de la desigualdad, observando el fenómeno desconectado de los modelos de desarrollo urbano y de las políticas públicas. Para otros autores más partidarios de la perspectiva «tradicional», periferia tiene connotaciones de espontaneidad, anomalía, deficiencia, subordinación, sugiere lo que "está al borde de lo urbano», lo no aceptado, calificado como desordenado y necesario de ordenar bajo los criterios de la «ciudad consolidada»; o, al enfatizar sus cualidades de frontera urbana, se concibe como «la expresión negativa de la modernidad urbana”, con sus connotaciones de espacio indefinido, anómalo, sin identidad. Otros proponen que, en la última década del siglo xx, este concepto ha cambiado radicalmente y surgen "nuevas periferias" que, rompiendo el paradigma tradicional, se caracterizan por la diversidad, los valores ambientales, la calidad de vida. De esta forma, afirman, podemos hablar de varias periferias con morfologías y características 
distintas. Frente al concepto clásico de periferia que "combina distancia y desorden físico, dependencia funcional y marginalidad social" (Arteaga, 2005:101), estas "nuevas periferias" se ordenan, pero con una lógica distinta a la de la "ciudad tradicional" o consolidada (Espallargas, 2016). Por lo tanto, deberíamos ver las periferias como procesos continuamente cambiantes más que como una entidad fija e inmutable en el tiempo. Este cambio hace referencia tanto a su localización urbana como a los valores que se les asignan y a las estrategias para abordarlas.

Entre esa "variedad de lugares", Arteaga (2005) sugiere que podemos encontrar tres tipos: la periferia industrial; la periferia residencial que tiene las connotaciones clásicas de "espacio incompleto" por la falta de servicios o por su imagen peyorativa; y "la periferia dispersa", fenómeno de finales del siglo xx, profundamente influido por la reestructuración económica y los avances tecnológicos y cuyos residentes lo eligen por sus características ambientales, por el modo de vida ligado a espacios verdes (por lo que Mario Gaviria llamaba en los años ochenta "la ideología clorofílica"), o por su tranquilidad o aislamiento (Espallargas, 2016), pero que carece de las connotaciones negativas de la periferia residencial. Son estos dos últimos tipos de periferia los que aquí nos interesan, por su común uso residencial.

Otros autores, como Ávila et alii (2005), apuestan por recuperar el significado «tradicional» de periferia, pero ligándolo a un proceso relacional, que establece un vínculo con un centro, en el cual se toman las decisiones y se concentra la riqueza (Ávila et alii, 2015: 130). Débora Ávila (2015), y en lo que se refiere a Madrid, habla de tres tipos de periferia residencial en función del momento en que aparecen y de su evolución histórica. La periferia obrera surgida de la emigración de los años sesenta del siglo $\mathrm{xx}$ desde las zonas rurales del país; en la actualidad, poblada por grupos de aquellos obreros hoy envejecidos pero también por la llegada de inmigrantes internacionales en los años ochenta; se conformó como una periferia socialmente homogénea y combativa, que logró, a través de sus luchas vecinales, viviendas y equipamientos sociales. Las sucesivas crisis, la irrupción de las drogas y el desgaste del movimiento vecinal han provocado una gran fragmentación del tejido social de estos núcleos obreros, rompiendo la homogeneidad social existente en la que se basaba su lucha. 
Un segundo tipo de periferia residencial lo representaría lo que esta autora llama "barrios guetificados", aquellos que no se beneficiaron del bienestar social de los años noventa, y quedaron atrapados en la exclusión y el abandono; son barrios que han surgido de los planes de realojo de la población chabolista, nunca integrados en los barrios obreros y mayoritariamente de población gitana o paya muy pobre. Estos realojos se realizaron en las zonas menos equipadas, de peor infraestructura y deficientes transportes. Se realojó a una población sin considerar ninguna de sus circunstancias sociales, bajo el único criterio de la disposición de espacio, sin tener en cuenta a los habitantes que allí residían. Esto implicó un incremento de los conflictos y las tensiones, y ante el incremento de la conflictividad, del abandono, de la pobreza y de la supervivencia informal, fueron estigmatizados por la prensa y los medios de comunicación. Con el cambio en el papel del Estado - de políticas distributivas a un Estado fundamentalmente dinamizador económico-, se ven invadidos por una fuerte intervención del Estado, de ONG y de empresas privadas, para monitorear, supervisar y encauzar a su población a través de infinitos programas de intervención, mediadores y/o trabajadores sociales, educadores de calle. En muchos casos, esa hiperintervención no soluciona ninguno de sus problemas, como demostró Ariadna Ayala en su tesis doctoral de 2014.

Por último, Ávila et alii también identifican un tercer tipo de periferia residencia que, en el caso de Madrid, se correspondería con los barrios ligados a los Planes de Actuación Urbanística. Estos planes establecían:

[... ] zonas alejadas del centro de la ciudad y situadas en la periferia bien comunicada y en la que se pensaba su desarrollo de manera integral, con zonas verdes $y$ áreas de servicios que, como siempre, sobre el papel conformaban un buen marco de estimulación imaginativa para los futuros pobladores (Martínez Aranda y López Díaz, 2016: 7).

Cueli (2016) y Ávila (2015) destacan la enorme diferencia entre aquellos que se desarrollan en el este y el sur de Madrid y aquellos del norte o el oeste madrileños, estos últimos concebidos para albergar a las nuevas clases medias del Madrid global. En los primeros, conviven en la misma calle grandes urbanizaciones de manzanas cerradas, piscinas y pistas de pádel, zonas ajardinadas 
e instalaciones deportivas en el interior, parques infantiles..., con bloques de protección social diseñados con formas originales, con tal combinación de colores que acaban identificando, señalando y marcando a su población pobre (Martínez Aranda y López Díaz, 2016).

Llegados a este punto, ¿qué conclusiones podemos sacar de esta intervención?

\section{Conclusión}

Un elemento en común que tienen ambas periferias es la inexistencia de bienes y servicios, de equipamiento e infraestructuras públicas. Las políticas públicas en ambos casos son ejemplos de lo que Neil Smith (2012) llama «ciudad revanchista» en su análisis de las políticas urbanas norteamericanas de los años noventa, cuando la guerra contra los pobres dio paso a un Estado penal, en el que los excluidos del empleo estable y el acceso a la vivienda fueron además perseguidos como delincuentes. Algunas de las características de la ciudad revanchista serían la protección de las rentas del capital, el estrangulamiento de las formas de reproducción colectiva y la persecución de la pobreza, y donde el gasto público se decanta finalmente como un mero instrumento de gobierno de las élites políticas y económicas, apenas compensado por el mantenimiento de unos servicios cada vez más asimilados a lo asistencial.

Ambas zonas reflejan los recortes en gastos sociales de las administraciones madrileñas, iniciados tras la crisis de 2008: sin equipamientos ni servicios, irregular transporte público — para acceder a ellas hay que utilizar el automóvil privado-, escasos comercios de proximidad sustituidos por el desarrollo de los grandes centros comerciales y/o la venta ambulante y el comercio informal. En los PAU, los espacios públicos están abandonados o a medio construir, y son ocupados por aquella parte de la población de escaso poder adquisitivo que reside, a menudo, en las viviendas sociales; y son esos pobres los que llevan a sus hijos a la escuela pública, mientras los residentes de los bloques privados envían a sus hijos a colegios privados o concertados. Lo público se queda reducido a la pobreza e identificado con lo asistencial. Estos pobres son los protagonistas de las dos instituciones de realojos y viviendas sociales de Madrid (la Agencia 
de Vivienda Social de la Comunidad de Madrid y la Empresa Municipal de la Vivienda y Suelo de Madrid) o los okupas procedentes de desahucios, o de los derribos de la Cañada, que dan la patada a la puerta de aquellas viviendas sociales sin adjudicar.

En los PAU los pobres necesitan unos recursos públicos casi inexistentes, mientras que las clases medias o profesionales prescinden de ellos: unos se mueven en coches privados por las grandes avenidas para ir a comprar o disfrutar de su tiempo libre, para ir a los colegios privados o concertados, para practicar un deporte o para ir a trabajar; los otros, los pobres usuarios de vivienda pública, van a la escuela pública, andando largos trechos para alcanzar un transporte público, compran en venta ambulante $y / o$ informal, intentando crear aquellos parques tan bonitos diseñados sobre el papel, fabricando sus bancos, adquiriendo y plantando árboles y flores. La coexistencia en un mismo espacio de aquellos que necesitan de lo público, hoy en día cuestionado y en franca reducción, y aquellos que suponen no necesitarlo (ni sus espacios, ni sus escuelas, ni sus equipamientos y servicios, ni sus agentes del orden) puede implicar un incremento de la conflictividad, la desconfianza, el rechazo al otro, como muestra Svampa (2005), para el caso de los condominios argentinos de clases medias desplazados hacia los suburbios en su aspiración por lograr similar estilo de vida de la élite argentina. Esto ya está sucediendo en el sector 5 de la Cañada a su paso por Rivas Vaciamadrid, donde desde los años noventa se ubicaron mayoritariamente familias inmigrantes de origen marroquí y en los últimos años, familias gitanas rumanas. En este tramo, la Cañada linda con la Cooperativa de Viviendas Baratas (COVIBAR), y la llegada de marroquíes siempre ha sido un elemento de conflicto y desconfianza, haciendo aflorar la xenofobia de los residentes. Pero la apuesta del Ayuntamiento de Rivas Vaciamadrid por un crecimiento municipal a base de urbanizaciones, mayoritariamente de chalés adosados, ha profundizado el problema y puede incrementar el conflicto y las presiones para que el Ayuntamiento ordene el derribo de viviendas de la Caña$\mathrm{da}$, suceso que, en este municipio y por primera vez en los 50 años de existencia de la Cañada, se llevó a cabo en noviembre de 2016.

Los PAU, que el Tribunal Supremo declaró ilegales en sentencia de 2013, por su transformación de suelo protegido en suelo urbanizable, surgieron para dar respuesta desde la administración pública al problema de la vivienda en Madrid, pero fueron dejados en manos de la iniciativa privada y sometidos al 
proceso de especulación urbana, inseparable del neoliberalismo. Estos PAU del sureste madrileño son los causantes del interés de las administraciones públicas por la Cañada, de los procesos de estigmatización de sus residentes, pero también de la lucha por conservar sus viviendas, por dotarse de identidad y por crear un barrio, luchas en las que aquí no podemos detenernos, pero sí recordar.

En la Cañada, surgida desde la población para dar respuesta al problema de la vivienda de los más pobres en Madrid, la administración pública solo se presenta en dos de sus facetas: asistencial, en forma de REMI (Renta Mínima de Inserción) y trabajadores sociales, es lo público transformado en asistencia o, últimamente y basándose en normativa técnica y urbanística «procedente de Europa», para legitimar sus derribos y el desalojo de los vecinos; o, en segundo lugar, también aparece en su versión represora: policías y sistema judicial interviniendo en derribos que no siempre tienen las garantías legales adecuadas o a través de redadas en búsqueda de traficantes de drogas reales o ficticios, tras un proceso de criminalización de la pobreza impresionante. Porque la privatización y la especulación no se pueden realizar sin una legitimación. Estigmatizar a sus habitantes, y al espacio que ellos ocupan, convertirlos en delincuentes $y$ drogadictos, es una manera efectiva de legitimar ese "crecimiento por desposesión" (Harvey, 2005). La estigmatización es una de las expresiones de la expropiación simbólica (Wacquant, 2007) y, por lo tanto, de violencia simbólica ejercida sobre los más desfavorecidos. En última instancia, la violencia simbólica es una naturalización de un orden social y cultural estructuralmente desigual. La distribución desigual del poder y los recursos en nuestras ciudades es el origen de la violencia, y el primer acto de violencia simbólica. Esa violencia simbólica sobre los más desposeídos de nuestras ciudades puede aplicarse también a través del uso de criterios exclusivamente técnicos y una normativa urbanística despiadada para demoler o mantener sus viviendas, en vez de aplicar criterios de ciudadanía y de derechos humanos. También es violencia definir un problema como "urbanístico" olvidando su faceta social. Y es este proceso una de las características de las intervenciones públicas actualmente en las periferias del sureste madrileño. 


\section{Bibliografía}

Aramburu, M. (2017). "Precario suburbanismo. Familias de clase media en urbanizaciones de baja densidad en Cataluña”. Revista de Antropología Social, 26(1): 31-51.

Arteaga, I. (2005). "De periferia a ciudad consolidada. Estrategias para la transformación de zonas urbanas marginales”. Bitácora, 1(9): 98-111.

Ávila, D. et alii (2015). "Viejas y nuevas periferias en la ciudad neoliberal: seguridad y desigualdad social”. En Ávila et alii (eds.). Enclaves de riesgo. Gobierno desigualdad y control social. Madrid: Traficantes de Sueños, pp. 127-161.

Ayala, A. (2012). "Las políticas sociales en perspectiva socio-antropológica: estudio de la gestión y aplicación de la Renta Mínima de Inserción de la Comunidad de Madrid con el colectivo gitano". [Tesis doctoral]. Madrid: Universidad Complutense de Madrid. Departamento de Antropología Social.

Bourdieu, P. (2002). "Espíritus de Estado. Génesis y estructura del campo burocrático”. En: <http://www.uruguaypiensa.org.uy/imgnoticias/1042. pdf> (última consulta el 19 de junio de 2017).

Caldeira, T. (2007). Ciudad de Muros. Gedisa: Barcelona.

Comunidad de Madrid (2017). Pacto Regional por la Cañada Real Galiana. Madrid: Comunidad de Madrid.

Foucault, M. (2007). Nacimiento de la biopolitica. Buenos Aires: FCE.

Espallargas, J. L. (2016). “Confort-mismo: relaciones, comportamientos, y construcciones de la identidad en las urbanizaciones residenciales. Habitantes suburbanos en la provincia de Tarragona". [Tesis doctoral]. Tarragona: Universitat Rovira i Virgili. Departamento de Antropología y Trabajo Social.

García, S. (2011) "Co-producción (y cuestionamientos) del dispositivo securitario en Carabanchel”. [Tesis Doctoral]. Madrid: Universidad Complutense. Departamento de Antropología Social.

González Cueli, I. (2016). "Donde las periferias cambian su nombre. Una aproximación al urbanismo y las relaciones sociales en las nuevas periferias urbanas del Madrid neoliberal". [Máster de Antropología de Orientación Pública]. Madrid: Universidad Autónoma de Madrid. Departamento de Antropología y Pensamiento Español. 
Harvey, D. (2005). “El imperialismo: acumulación por desposesión”. Red de Bibliotecas Virtuales de CLACSO, <http://biblioteca.clacso.edu.ar/clacso/se/20130702120830/harvey.pdf> (última consulta el 20 de julio de 2017).

Low, S. (2006)."The Erosion of Public Space and the Public Realm: paranoia, surveillance and privatization in New York City". City and Society, 18(1): 43-49.

Low, S. (2003). Behind the Gates: life, security and the porsuit of hapiness in Fortress America. Nueva York: Routledge.

Low, S. (2001). "The Edge and the Center: Gated Comunities and the Discourse of Urban Fear". American Antbropologist, 103(1)ः 45-58.

Martínez Aradan, D. y López Díaz, J. (2016). “Por qué las viviendas sociales han de tener fachadas de colores?". Comunicación al Congreso de Contested Cities, Eje 2, Artículo n* 2-520: 1-18.

Mas Hernández, R. (1999). "Periferias urbanas y nuevas formas espaciales". Biblioteca Virtual Universal. <http://biblioteca.org.ar/libros/132823. pdf> (última consultado el 19 de julio de 2017).

Monreal, P. (2014). "Imágenes y representaciones de un espacio urbano: el papel de los medios de comunicación en la reproducción de las desigualdades". Antropológica PUCP, 33(33):39-66.

Monreal, P. (2014b). "Procesos de estigmatización, especulación y resistencia en la Cañada Real Galiana a su paso por Madrid”. En Lundsteen, M.; Martínez Veiga, U. y Palomera, J. (coords.), Reproducción social y conflicto en las periferias urbanas del Estado español. Actas del XIII Congreso de Antropología Tarragona. Universitat Rovira i Virgili.

Monreal, P. (2015)."Madrid como ciudad neoliberal: estigmatización de un asentamiento informal y especulación urbana”. En Zamanillo, M. (ed). La ciudad y la vida urbana. Erasmus, XVI (2): 113-136.

Sмith, N. (2012). La nueva frontera urbana. Ciudad revanchista y gentrificación. Madrid: Traficantes de Sueños.

Svampa, S. (2005). Los que ganaron. La vida en los countries y barrios privados. Buenos Aires: Biblos.

Valenzuela, M. (2003). "La residencia secundaria en ámbitos metropolitanos: la comunidad de Madrid”. Estudios Turísticos, 155-156: 112-157 
Vaquerizo, E. (2015). "La arquitectura de la «nueva periferia»: dinámicas socioculturales urbanas en el PAU de Vallecas". Revista de Dialectología y Tradiciones Populares, 70(2): 503-526.

Vaquerizo, E. (2017). "Un nuevo espacio público para un nuevo desarrollo urbano: la creación de un ecobulevar en la periferia de Madrid”. En TомÉ, P. (ed.) Reflexiones Rayanas, vol. 2. Ávila: Asociación de Antropología de Castilla León Michael Kenny, pp. 101-123

Wacquant, L. (2013). “Tres pasos hacia una antropología del neoliberalismo real”. En: <http://www.herramienta.com.ar/revista-herramienta-n-49/ tres-pasos-hacia-una-antropologia-historica-del-neoliberalismo-real> (última consulta el 19 de junio de 2017).

Wacquant, L. (2007). Los condenados de la ciudad. Gueto, periferias y Estado. Buenos Aires: Siglo XXI. 